\title{
Trauma Surgery $\&$ Acute Care Open \\ The American Association for the Surgery of Trauma Diversity, Equity and Inclusion Committee Essay Contest: Voices of the Future
}

\author{
Cherisse Berry
}

Surgery, New York University Grossman School of Medicine NYC Health + Hospitals/ Bellevue, New York, New York, USA

Correspondence to Dr Cherisse Berry; cherisse. berry@nyulangone.org

Received 18 November 2021 Accepted 19 November 2021

\section{Linked}

- http://dx.doi.org/10.1136/ tsaco-2021-000864

- http://dx.doi.org/10.1136/ tsaco-2021-000853

(c) Author(s) (or their employer(s)) 2021. Re-use permitted under CC BY-NC. No commercial re-use. See rights and permissions. Published by BMJ.

To cite: Berry C. Trauma Surg Acute Care Open 2021:6:e000867.
The American Association for the Surgery of Trauma Diversity, Equity, and Inclusion (AAST DEI) committee was established in 2019 by Immediate Past President Dr. David Spain. The work of the committee furthers the mission of the AAST of being dedicated to discovery, dissemination, implementation, and evaluation of knowledge related to acute care surgery (trauma, surgical critical care and emergency general surgery) by fostering research, education and professional development in an environment of fellowship, collegiality, inclusion, diversity and equity. Under the exemplary leadership of the Immediate Past Chair Dr Karen Brasel, the AAST DEI committee was awarded one of the inaugural American College of Surgeons (ACS) Board of Reagents Innovative Grants for DEI \& Anti-Racism. The $\$ 25,000$ grant will be matched by the AAST and the co-sponsoring societies including the ACS Committee on Trauma (ACS-COT) and the Pediatric Trauma Society (PTS). One of the three specific aims of the grant is to develop a pipeline of under-represented racial/ethnic minority students interested in surgery, trauma, and medicine. As described so eloquently by ACS Regent, Dr Timothy Eberlein, "America is changing. It's becoming much more diverse. As we think about the last 18 months with the pandemic, US minorities are disproportionately affected by health care disparities. Increasingly, diversity in healthcare professionals, particularly our surgical subspecialties can have a major impact. For sure, leading a diverse surgical workforce will have better quality of care and will provide a much more conducive and better learning environment. It will increase creativity and innovation for all students. A more diverse workforce will lead us to providing better, more equitable, and more inclusive research questions...Having diversity and inclusion will create a higher business performance with better outcomes...the creation of much better teams... and will create better access to care for the underserved who we all provide care for." Thus, to help fill a diverse pipeline, we must support, encourage, sponsor, and be intentional in recruiting medical students, residents, and fellows from underrepresented groups as they pursue a career in acute care surgery.

One of the missions of the AAST-DEI committee is to provide career development opportunities for surgeon scholars and leaders from diverse backgrounds. Because the path to scholarship and leadership begins early, one of the committee's first initiatives that aligns with this mission was to sponsor an essay contest for medical students, residents, and fellows. The 2020 winning essays were recently published in TSACO and scholarships to attend the 2021 annual meeting in Atlanta, GA, were awarded to the first-place winners. This year, the winning essays were again outstanding and powerful. We look forward to welcoming the firstplace winner Dr Toba Bolaji to the 2022 annual meeting in Chicago, IL, and we are thrilled to be able to publish Dr Bolaji's essay along with the essay of the second-place winner, Dr Sarah CottrellCumber, here.

The winning essay responded to the following prompt:

- Why I am interested in Acute Care Surgery as my Career

\section{FIRST PLACE}

\section{Superhero}

Dr. Toba Bolaji is a fourth-year general surgery resident at ChristianaCare in Newark, DE. He grew up in Toronto, Canada, then completed his undergraduate degree at Robert Morris University, where he was a Division I soccer player. He received his medical degree at Philadelphia College of Osteopathic Medicine. $\mathrm{He}$ is a writer, triathlete and is pursuing a career in trauma/critical care and acute care surgery.

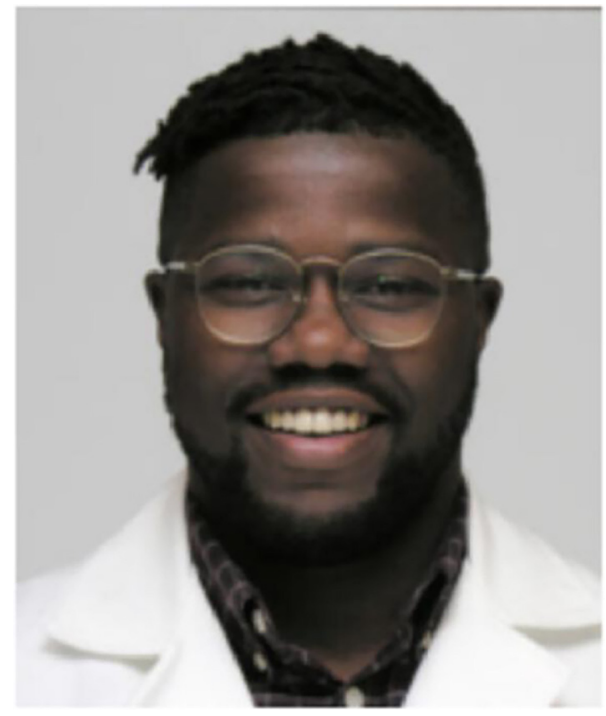




\section{SECOND PLACE}

Cut to ease suffering

Dr. Sarah Cottrell-Cumber is a third-year general surgery resident at the University of Mississippi Medical Center. She has an interest in racial disparities and outcomes regarding integration of palliative care into the care of critically ill trauma patients. When not at the hospital, Sarah and her partner Matt enjoy exploring Mississippi with their four dogs.

Contributors I am the sole contributor for this introduction of the 2021 AAST DEI Winning Essay.

Funding The author has not declared a specific grant for this research from any funding agency in the public, commercial or not-for-profit sectors.

Competing interests None declared.

Patient consent for publication Not applicable.

Provenance and peer review Commissioned; internally peer reviewed.

Open access This is an open access article distributed in accordance with the Creative Commons Attribution Non Commercial (CC BY-NC 4.0) license, which permits others to distribute, remix, adapt, build upon this work non-commercially, and license their derivative works on different terms, provided the original work is properly cited, appropriate credit is given, any changes made indicated, and the use is non-commercial. See: http://creativecommons.org/licenses/by-nc/4.0/.

\section{ORCID iD}

Cherisse Berry http://orcid.org/0000-0002-1683-6940 